This is an electronic reprint of the original article. This reprint may differ from the original in pagination and typographic detail.

Author(s): Maunula, Minna

Title: $\quad$ E-Exam Questions and Meaningful Learning

Year: $\quad 2016$

Version:

Please cite the original version:

Maunula, M. (2016). E-Exam Questions and Meaningful Learning. In L. G. Chova, A. L. Martínez, \& I. C. Torres (Eds.), EDULEARN16 Proceedings. 8th International Conference on Education and New Learning Technologies (pp. 1563-1568). IATED Academy. EDULEARN proceedings. https://doi.org/10.21125/edulearn.2016.1310

All material supplied via JYX is protected by copyright and other intellectual property rights, and duplication or sale of all or part of any of the repository collections is not permitted, except that material may be duplicated by you for your research use or educational purposes in electronic or print form. You must obtain permission for any other use. Electronic or print copies may not be offered, whether for sale or otherwise to anyone who is not an authorised user. 


\title{
E-EXAM QUESTIONS AND MEANINGFUL LEARNING
}

\author{
Maunula Minna \\ University of Jyvaskyla, Kokkola University Consortium Chydenius (FINLAND)
}

\begin{abstract}
Traditionally exams are seen as one of the important learning situations and as possibilities to verify the learning processes in universities. In academic contexts exams are used actively, and they still play an important role. From a pedagogical point of view, exams are also criticized - do exams promote high-quality learning? Current learning theories highlight the active role of the individual learner and skills for future working life. At the same time the changes in the operating environment are huge and the pace of development is high, which also challenges academic practices. Digital revolution forces and allows for learning in different contexts. Different web-based solutions are developing strongly and are in active use in academic contexts, also in the open university. Webbased solutions can promote equal opportunities to participate in lifelong learning for the adult students. For example, e-exams help and sometimes enable academic studies for adult students. In the article the experiences of the adult students of the open university regarding e-exam questions and the meaningfulness of their own learning process are examined.
\end{abstract}

Keywords: e-exam, meaningful learning, academic adult education, open university.

\section{INTRODUCTION}

Many technological-pedagogical applications of the digital age are developed based on the practical needs and the different users' experiences [for example, $1 ; 2 ; 3 ; 4 ; 5 ; 6]$. In this case the open university e-exams were developed due to students request to study from a distance. The first eexam, which was at first called a timed e-assignment, was piloted in 2009 in the methodology course of the educational studies subject level study modules. After that, good practice spread and is now part of the open university everyday study practices. Practically, e-exam participants write their eexam-answers on their own computers at home. E-exams require preregistration and the students prepare for the e-exam in the normal way by reading the literature mentioned in the curricula. The students have four hours in which to answer and send their answers via the system. They are allowed to use all the materials possible during the e-exam. E-examinations are held once every month.

The open university adult students already have strong and individual knowledge and skills which are central to building individual expertise [7; 8]. The main goal in academic education is to confirm individual learning and to create opportunities to combine informal and formal learning in academic contents. The open university teachers' role is more to supervise and to enable learning by combining new learning environments, digital possibilities, academic contents and individual interests [eg. 9; 8; 7].

\section{GLOBAL DIGITALIZATION IN EDUCATIONAL CONTEXTS}

\subsection{Continuous development as a starting point}

The different digital innovations have become of part a everyday life in the universities. The multiformity of the learning environments and the utilization of digital methods have extended the idea of the individual learning processes. In the heated development the new concepts are variedly used and indeed even the established ones have become blurred. The inaccuracy of the concepts and the constant change challenge the researchers, the developers on the front line and the users. [10.]

Ubiquitous learning environments that are invisible and adaptable everywhere are developed and tailored according to individual needs; [3.2]. For example the lectures have transferred to web-based recordings independent of time and the place to an increasing extent in the academic adult education [4]. A supervisor of the learning and the peers in the same situation support the individual learning processes [11] and are quickly available through the network. Also attention has been paid to the authenticity and changing global contexts in the assignments [12; 13]. 


\subsection{Starting points for adult learning}

Learning for an adult is attached to everyday life, it overlaps with the genuine contexts of operation in a meaningful way [14] and it is made possible by recognizing the factors distributing an adult's time resources. The digital solutions will make the studying possible in the middle of one's own everyday life $[2 ; 1]$ but it requires strong self-direction. As an adult, learning takes place in the dialogue between the different contexts; in the middle of everyday life, work and family [15] but also online.

The different web-based environments which make the learning possible challenge us [14] to consider e-pedagogics and, on the other hand, also the deepest essence of meaningful learning. Learning is always a series of personal events and a constant process in which the adults especially have individual participating factors [8]. For learning to be genuine as an adult, it requires the effect of the experience [7]. The adults themselves must be given the responsibility, they have to be relied upon and to be encouraged to find personal meaningfulness for the learning [also 14; 16]. In the eexamination the essential starting point is to take the opportunities for learning to the centre of an adult student's everyday life $[1 ; 2]$ and in this way to improve the flexibility and flow of the studies at the same time. It is obvious that e-teaching is developed globally but by also paying attention to local and individual needs.

\section{METHOD}

In this case of the open university that I examine, the academic adult students' request for expanding distance learning was responded to by creating the first version of the e- exam. After piloting, the practices were developed on the basis of the experiences. At the first stage, for example, the examination was "controlled" through the students' web-cameras but the practice was soon given up. With the positive experiences the practice was extended and its development is still continuing. Because the students study from different locations and the supervision is a challenge, it was clear in principle, that the students could utilize the literature and, for example, the other sources which are found in the Internet during the examination. Because of this the exam questions which require the application and consideration of wider units were seen as a pedagogical solution for profound learning. The exam question could not be answered briefly or by repeating the information in the literature but comprehensively and by using one's own thoughts. At the same time, the restriction was time, the duration of the examination was only four hours.

The analyzed material is the open university students' e-exam answers. The material is collected during three academic years (2013-2014, 2014-2015, 2015-2016). The students participated in the educational studies at Bachelor level. In e-exams, the last and the optional question concerned the adult students' own learning process, feedback concerning the e-exam, how students self-evaluated the e-exam questions and their own meaningful learning process. In the analysis process the students' feedback and thoughts about the e-exam were examined. The answers were analyzed on the basis of the contents, first the positive and the negative experiences and then classified in more detail according to the contents. The authentic students' experience descriptions are presented amongst the results.

\section{RESULTS}

\subsection{Adult students in e-exam: initial stress, technique and preparation}

The adults students of the open university were novices in many respects in regard to the eexamination which was reflected in the comments and evaluations. They told that they had felt nervous about participating in the e-exam a lot before the actual e-exam. They brought out their tension about the functioning of the technology and a few mentioned feeling terrified about the examination.

"The e-exam made me very nervous beforehand, what are the questions, have I got time to look for the answers even if I had prepared for them. I also thought about if I can form a structured answer in the required time or my own views to support the answers."

Different problem situations had been prepared for in the open university. The examination was "supervised" by a person that could be reached by phone. Furthermore, the detailed written instructions were prepared for in the e-exam environment. None of the participants' performance fell in 
technical difficulties. Often the students called and made sure that their exam answers had arrived in their web-based submission folder.

According to the students, the e-exam on the home computer required careful preparation and anticipation of many matters but was suited to their busy situation in life. The students were extremely satisfied with the opportunity to participate in the examination form that was also time efficient from another locality or even from another country.

"The e-exams made my studying possible. I just couldn't divide my exam time so that it would be enough for properly thinking and writing every answer. This is my problem, however well I would read and prepare for examinations."

"The e-exams had proved to be the best way to study for me. When I have an exact time for when I must do something, then it gets done. Furthermore, I like the questions where my own thoughts must be used. Not too difficult but not too easy either. It made me think about my own views."

The students mentioned limiting factors to do with the time usage, the date of the e-exam gave structure to the studying process. Factors which are connected to the use of time and to learning of contents were linked to the e-exam and to evaluating their own learning. On the other hand, preparing for the e-exam was challenged by the difficulties of getting hold of the examination literature. Also understanding the literature to be examined in a foreign language had made the learning process and preparing for the e-exam more difficult.

\subsection{Learning of academic contents}

\subsubsection{What is asked and how?}

The e-exam questions are drawn up by the teachers responsible for the different study modules. They have the freedom to draw up the questions independently but the learning objectives of the curriculum and literature direct the compilation of questions. During the e-exam also the adult pedagogical starting points and the materials used by the students are directed at the application questions. The question types of the e-exam are directed at handling a wide range of contents in a tight form and to connect thinking to the current phenomena and everyday life. The reflection of the practical and experiential dimension on to a theoretical frame of reference is possible in the exam questions. The general starting point is to examine authentic contexts and change from a certain point of view and to evaluate from the perspective of different agencies. Also the open starting point is possible in which case the students are given the opportunity to think about the learned contents from their own starting points.

\subsubsection{Meaningful to answer to - too little time}

The e-exam questions were experienced in different ways: both difficult and extremely meaningful for own learning. The adult students of the open university appreciated examination questions which made wide considerations possible but the answer was not found from one source or from a few items of the examination literature, not to mention from individual pages. A wide, but open-ended and clear e-exam question was even a positive surprise which reduced the tension experienced in the beginning of the e-exam. Getting started strengthened confidence in one's own knowledge and in managing the e-exam.

"I was nervous about the e-exam, the subject is also a little challenging for me. I gave a sigh of relief once the question came up. It was short and precise and was to do with the whole study module and the answering possibilities and points of view were huge. I was afraid that there would be a question which requires exact information. In my opinion, a question just like this is extremely important, you can condense everything you have learned into a tidy package. I was positively surprised how well and how much I had learned. At the initial stage I thought that there was plenty of time, but in the end the whole four hours must be utilized at a good pace and with careful consideration."

"I should have perhaps made the notes also of those thoughts which I had when reading, I would have gotten a lot out of them. On the computer I was really worried that I would not have enough time to return the work!"

The students who had participated in the e-exam stated the limited time and scope of the contents to be examined as a challenge. Organizing the contents into a compact and versatile unit which would 
include one's own thoughts was seen as a challenging task to perform in four hours, there would have been much more to write and to add. However, the students were mainly cautiously satisfied with their own performance. At the same time, however, they told that given more time they would have achieved a more structured answer. Also, according to also the students' own evaluations, the broad question and the limited time directed concentration on the essential and, on the other hand, to careful preparation beforehand. Leaving out a large number of details from the answer raised uncertainty. The production of a fluent essay type text with its references also brought on pressure.

\subsubsection{Rewarding preparation}

From the point of view of learning the contents of the e-exam got good evaluations. Preparing for the e-exam had been efficient time-wise and profound, the new form of performance had activated the self-assessment of their own learning process. Preparing for the e-exam had reduced cramming for the exam and had increased the understanding of the learning process. Different notes and mind map style significance networks had been drawn up from the contents.

"I regarded it as fruitful, it reduced "cramming" and the type of learning where information is just stored in the brain short term and used quickly. There is an opportunity for wider combining and consideration of the matters in the e-exam. From the point of view of my own learning the e-exam worked well. I looked at my own mind maps and tried to form the answers from them."

Participation in the e-exam, especially the preparation for it was processing which crystallizes the contents. In the e-exam the whole unit still continued to condense which was evaluated as useful from the point of view of one's own learning process. According to the students, the broad question included the whole course area and helped to form a general impression of it. It was positive when in the answer of the e-exam the students could reflect the studied contents to their own experience, which had been natural also when reading the exam literature. A good examination question was evaluated as down-to-earth, compelling and, furthermore, the contents were connected to one's own professional experiences. In brief, the e-exam questions directed the use of one's own thinking and deepened the understanding both of the contents to be studied and of one's own operation.

"This was really nice because when reading the whole course material, I reflected upon my own life and sometimes laughed by myself thinking "that's how it is."

The examination question was well drawn up, it required students to crystallize their own thinking based on all the reading and to create a collated answer which is not a direct repetition which follows the line of any literature but requires internalization of matters because in the question the examining of the points of view from the sources and articles has been asked from a different point of view. Furthermore, the exams serve as a recap where the student still recalls what has been learned and prepares an answer which also brings out also their own thinking and is based on the reading. I at least still experience that I am internalizing the contents better through the process of writing with my own words and joining the points of view of different sources. The learning would be left considerably more superficial without this process.

The students gave excellent feedback on the e-exam questions apart from a few exceptions. The eexam questions required application and made it possible to link one's own considerations to the literature to be examined. According to the students, it was best was that the contents were not studied by heart but learning took place from one's own starting points and genuinely challenged one's own understanding. The good e-exam question both condensed the core of the unit to be learned and directed the crystallization of one's own learning and to attach the examination to genuine contexts. According to one student's consideration, the question of the e-exam had succeeded when an answer could be drawn up also by the ones with weaker skills but it would also allow for the more skilled students to show their ability.

\section{CONCLUSION}

One can state that the digital development has for its part promoted pedagogical meaningful solutions. The academic adult students' learning experiences which are related to the e-exam are strongly positive. The starting point of the e-exam which activates student's own thinking and applies the experience which has been acquired in the contexts of the adults' working life as well as the contents to be studied and, on the other hand, the practices which rationalize the academic adult student's use of time promote high-quality learning. Digital revolution helps lifelong learning. 
According to the students, the e-exam was exciting and a new learning experience. They were satisfied with the possibility to participate in the e-exam at home, it fitted in well in their life situation, saved time and intensified studies. Good e-exam questions were clear, broad and enabled reflection. The e-exam was reflected upon as a crystallizing experience. Good question helped to summarize the core content and answering combined with one's own reflection deepened the experienced learning. The e-exam seems to support meaningful learning if e-exam questions are planned from the adult pedagogical point of view. New technologies can diversify adult students' learning processes in open university, e-exams promote integrative adult pedagogy and strengthen the required digital and other generic skills. One has to remember that experience is the adult learner' s living textbook [16], in other words, the nature of the e-exam is suitable for experiential starting points of an adult student. Furthermore, the e-exam creates equal study opportunities also in the centre of the factors which are part of the adults' everyday life.

\section{REFERENCES}

[1] Isosomppi, L. and Maunula, M., (2014). Adult Students in Web-based Thesis Seminars: Insights and Challenges for Supervision. Proceedings of MAC-ETeL 2014. Multidisciplinary Academic Conference on Education, Teaching and E-learning. Prague, Czech Republic, pp. 1-8.

[2] Maunula, M. and Isosomppi, L., (2015). Developing Web-Based Academic Adult Education: Learning Experiences as Starting Points for Planning and for Continuous Development. In The International Journal of Interdisciplinary Educational Studies, Vol. 10(2), pp. 27-37.

[3] Hakala, I., \& Myllymäki, M. (2013). Ubiquitous Learning Environment Based on Lecture Videos. In Proc. Int. Conf. Education, Research and Innovation.

[4] Hakala, I., \& Myllymaki, M. (2014). Video sharing application for educational use: Usability and impacts of participation modes. In Emerging eLearning Technologies and Applications (ICETA), 2014 IEEE 12th International Conference on (pp. 343-348). IEEE.

[5] Kuikka, M., Kitola, M. \& Laakso, M.-J. (2014). Challenges when introducing electronic exams. Research in Learning Technology, 22.

[6] Herrington, J., Reeves, T. C. \& Oliver, R. (2006). Authentic tasks online: A synergy among learner, task, and technology. Distance Education 27 (2), pp. 233-247.

[7] Malinen, A., (2000). Towards the Essence of Adult Experiential Learning: A Reading of the Theories of Knowles, Kolb, Mezirow, Revans and Schön. Ph.D. thesis, University of Jyväskylä, Finland.

[8] Knowles, M. (1980). The modern practice of adult education. New York: Cambridge Book Company.

[9] Glickman, C. D., Gordon, S. P., \& Ross-Gordon, J. M. (2001). Supervision and instructional leadership: A developmental approach. Allyn \& Bacon/Longman Publishing, a Pearson Education Company, 1760 Gould Street, Needham Heights, MA 02494. Web site: http://www. abacon. com.

[10] Moore, J. L. \& Dickson-Deane, C. (2010). e-Learning, online learning, and distance learning environments: Are they the same? Internet and Higher Education 14 (2011), pp. 129-135.

[11] Chu, R. J., \& Chu, A. Z. (2010). Multi-level analysis of peer support, Internet self-efficacy and elearning outcomes-The contextual effects of collectivism and group potency. Computers \& Education, 55(1), pp. 145-154.

[12] Leppisaari, I., Vainio, L., \& Herrington, J. (2009). Developing authentic e-learning through virtual benchmarking. In World Conference on Educational Multimedia, Hypermedia and Telecommunications, Vol. 2009(1), pp. 2609-2618).

[13] Herrington, J. \& Oliver, R. (2000). An instructional design framework for authentic learning environments. Educational Technology Research and Development 48, pp. 23-48.

[14] Jonassen, D., Howland, J., Marra, R. M., \& Crismond, D. (2008). Meaningful Learning with Technology 2008 edition. 
[15] Maunula, M. (2015). Building Individual Expertise in Doctoral Studies the Significance of Everyday Experiences and Changing Contexts. Procedia-Social and Behavioral Sciences, 174, pp. 2326-2330.

[16] Lindeman, E. (1926). The meaning of adult education. New York: New Republic. 